\title{
Nacer (o también "morir") con dignidad: un objetivo problemático para el embrión*
}

\section{Francesco Donato Busnelli*}

Resumen. Partiendo de la consideración de la subjetividad del embrión, este artículo analiza los problemas asociados a la disposición de los embriones supernumerarios, y las implicaciones éticas y jurídicas de una posible destinación de estos para la investigación científica.

Palabras clave: disposición de embriones, muerte del embrión, investigación científica, derecho europeo, familia y nuevas tecnologías, dignidad humana.

\section{Being Born (or also "Dying") with Dignity: A Problematic Target for the Embryo}

Aвstract: Based on the consideration of the subjectivity of the embryo, this article analyzes the problems associated with the disposition of supernumerary embryos, and the ethical and legal implications of a possible destination of these for scientific research.

Keywords: Embryo disposition, embryo's death, scientific research, European Law, family and new technologies, human dignity.

Trad. del italiano, Natalia Rueda.

Publicado originalmente en Nuova giurisprudenza civile commentata, n. $^{\circ}$ 3, 201 7, 393-403.

Fecha de recepción: 25 de enero de 2018 . Fecha de aceptación: I4 de mayo de 2018.

Para citar el artículo: Busnelli, F. D., "Nacer (o también "morir") con dignidad: un objetivo problemático para el embrión", Revista de Derecho Privado, Universidad Externado de Colombia, n. ${ }^{\circ}$ 35, julio-diciembre 201 8, 77-103. Dor: https://doi.org/Io.1 8601/o I 234366.n35.04

** Profesor emérito de Derecho Civil de la Scuola Superiore Sant'Anna, Pisa, Italia. Doctor en Derecho. Contacto: fd.busnelli@gmail.com 
Sumario: i. Del dilema al problema. ir. Las novedades 'de la época': la aparición de las nuevas tecnologías y la afirmación de un derecho europeo. III. El 'diálogo entre las Cortes'. Europa llama: matrimonio y filiación escinden sus destinos. Iv. La Corte Constitucional responde: la 'intervención demoledora' de la Ley 40 de 2004. v. El viraje hacia la 'cultura del deseo'. vi. El desembarco en la 'cultura del descarte'. viI. Alea iacta est. viII. 'Tu l'as voulu!'. Ix. Invocar una intervención del legislador no es una novedad. x. Cruzar el Rubicón. xi. La cuestión de la 'muerte'. XII. Algunas pocas ideas para el legislador que quiere intervenir. XIII. ¿Qué queda de la Ley 40? La subjetividad del embrión. Referencias.

\section{Del dilema al problema}

"El dilema: ¿el embrión es un simple 'objeto', destinatario de posible manipulación, o es un verdadero 'sujeto', detentador de aquella dignidad personal que exige respeto absoluto?”. Esto se planteaba el cardenal Dionigi Tettamanzi hace 30 años ${ }^{\mathrm{I}}$.

Luego de 30 años, este dilema todavía no encuentra una respuesta clara y unívoca; por el contrario, se convirtió en un problema complejo, que desafía el carácter de imprescindibilidad de la alternativa propia del derecho romano -personae aut res- para terminar en gaseosas perspectivas de hipotético tertium datur o, más simplemente, para eludir la cuestión, a veces en una "dead end" road".

Esta transición del dilema al problema se puede encontrar tanto en la jurisprudencia italiana como en la europea.

La Corte Constitucional italiana, en la reciente sentencia en materia de investigación sobre los embriones 3 , habla de forma críptica del "estatus constitucional" del embrión, "como una entidad que posee el principio de la vida (si bien en un estadio de desarrollo no predefinido por el legislador y todavía no identificado unívocamente por la ciencia)". Allí trae a colación, de manera expresa, las conclusiones que emergen de la propia jurisprudencia.

Por su parte, la Corte de Casación privilegia de forma cuestionable "un enfoque metodológico que pone entre paréntesis todo lo que concretamente no es indispensable para recoger la esencia de lo que se investiga". En una reciente

I D. Tettamanzi, Bambini fabbricati. Fertilizzazione in vitro, embryo transfer, Casale Monferrato, I 985,8 o.

2 Pensamos en la película de William Wyler, "Dead end", г937.

3 Corte Const. I3 de abril de 20I6, n. 84, en Foro it., 20I6, I, I 509, con nota de G. Casaburi, $L a$ corte costituzionale e la l. 4 o del 2004: ritorno all'ordine? La cuestión, propuesta por el Tribunal de Florencia tenía como objeto los tres primeros incisos del artículo i3 de la Ley 40 de 2004 en contraste con los artículos 8, 32 y 33 de la Constitución (ord. I 2 diciembre 2oI 2, en Nuova giurisprudenza civile commentata, $20 \mathrm{I} 3$, I, 589 , con Nota di commento de G. Di Rosa, "Scienza, tecnica e diritto in recenti applicazioni giudiziali della disciplina in materia di procreazione medicalmente assistita"). 
decisión de las Secciones Unidas llega a la apresurada conclusión de que "no es indispensable elevar el nasciturus a sujeto de derecho" para dirimir el contraste de valoraciones que surge "respecto de la legitimación del nacido para pretender la reparación del daño por malformaciones en el momento del nacimiento"4 (se trata de la versión italiana del famoso affaire Perruche, que vio oponerse en Francia a la Corte de Casación y el legislador).

Mientras tanto, la jurisprudencia europea no ha dejado de exhibir una situación de incertidumbre, causando una paradójica inversión de roles entre sus cortes. En 2007 la Gran Sala de la Corte de Estrasburgo, institucionalmente encargada de la 'protección de los derechos del hombre' -moderno Don Abbondio5-, afirmó que, "ante la falta de un consenso unánime a nivel europeo sobre la definición científica y jurídica del inicio de la vida humana", dicha definición se deja a la competencia de cada Estado: en el caso en cuestión, teniendo en cuenta que el derecho inglés no reconoce la subjetividad del embrión desde la concepción, la destrucción de embriones luego de revocada su conservación no se consideró violatoria del artículo 2 del Convenio para la Protección de los Derechos Humanos y de las Libertades Fundamentales que, como se sabe, prevé el derecho a la protección de la vida humana ${ }^{6}$ (caso Evans c. Reino Unido).

Cinco años después, la Gran Sala de la Corte de Justicia de la Unión Europea respondió a la misma cuestión afirmando que "si bien la definición del embrión humano constituye un tema social particularmente delicado en numerosos Estados miembros, marcado por la diversidad de valores y tradiciones", la noción de embrión humano "debe entenderse en sentido amplio: así, desde el momento de su fecundación cualquier óvulo humano debe considerarse como un 'embrión humano"” (Caso Brïstle v. Greenpeace).

4 Cas., Secciones Unidas, 22 de diciembre de 2015 , n. 25767 , en Nuova giurisprudenza civile commentata, 20I6, I, 443 ss., con Nota di commento de F. Piraino, "I confini della responsabilità civile e la controversia sulle malformazioni genetiche del nascituro: il rifiuto del c. d. danno da vita indesiderata", $45^{\circ}$ ss., y la Opinione de C. M. MazzonI, "Vita e non vita in Cassazione. A proposito di Cass. n. ${ }^{\circ} 25767 / 2015 ", 46$ I ss.

5 Nota de trad.: personaje de la novela I promessi sposi de Alessandro Manzoni, que entró en la cultura popular italiana como ejemplo de persona poco resoluta.

6 Tribunal Europeo de Derechos Humanos (теDH), Gran Sala, Io de abril 2007, n. 6339/2005, N. Evans v. Reino Unido, en Nuova giurisprudenza civile commentata, 2007 , I, I 238 ss.

7 Tribunal de Justicia de la Unión Europea, I8 de octubre de 20 I I, causa C-34/1o, O(livier) $B$ (riistle) v. Greenpeace y V., en La Nuova Giurisprudenza Civile Commentata, 201 2, I, 289 ss., y Nota di commento de R. Romano, "La brevettabilità delle cellule staminali embrionali umane", ivi, II, 233 ss. La misma Corte regresó al argumento (con sentencia del I 8 de diciembre de 20I4, causa $\mathrm{C}-364 / 13$, caso Comptroller, ibíd., 2014, I., 4I 2 ss.) decidiéndose por la patentabilidad de las células estaminales derivadas del llamado "partenote", considerando que no se trataba de un embrión porque estaba desprovisto de la capacidad inherente de completar el proceso de desarrollo, sin posteriores manipulaciones. ¿Aclaración o corrección?: por la primera respuesta propende la Nota di commento de R. Romano, "Certezza del diritto, incertezza della scienza: della brevettabilità dei metodi di produzione di linee di cellule staminali da partenoti", ibíd., II, p. $3_{62}^{6}$, partiendo de la consideración de que "es la misma noción de embrión la que resulta 
Es necesario precisar desde ya que la norma sometida a interpretación no era el artículo 2 del Convenio sino el artículo 6, numeral 2, literal c, de la Directiva n. ${ }^{\circ}$ 98/44/CE, que considera "no patentables [...] los usos de embriones humanos para fines industriales y comerciales": "la Corte no está llamada a afrontar cuestiones de naturaleza médica o ética -se lee en la motivación- [sino] a remover los obstáculos a los intercambios comerciales y al buen funcionamiento del mercado interno, derivados de las divergencias legislativas y jurisprudenciales entre Estados miembros", sometiendo el texto de la directiva -que "no ofrece una definición del embrión humano ni reenvía a los derechos nacionales"- "a una interpretación autónoma y uniforme", para enfrentar "el riesgo de que los autores de algunas invenciones biotecnológicas sean tentados a pedir la patentabilidad de estas en los Estados miembros más permisivos".

De todas maneras, la Corte de Justicia, llamada específicamente a pronunciarse en vía prejudicial "sobre la interpretación del derecho de la Unión”, intentó dar una respuesta: respuesta que, aunque circunstancial y finalizada "al buen funcionamiento del mercado", no ha dudado en evocar el principio de "respeto de los derechos fundamentales y, en particular, de la dignidad humana”, teniendo en cuenta el revés de la histórica sentencia sobre el caso Omega $a^{8}-9$.

refinada, refiriéndola a los solos organismos en los cuales exista la potencialidad de expresar el todo".

8 Tribunal de Justicia de la Unión Europea, I4 de octubre de 2004, C-36/o2, Omega Sielhallen - und Automatenaufstellungs GmbH v. Oberburgermein der Bundesstadtsterin Bonn, en Corriere Giuridico, 2005, 486 ss., con Nota di commento de R. Contı, "La dignità umana dinanzi alla Corte di Giustizia”.

9 Nota de trad.: el caso al que se refiere el autor corresponde a una controversia respecto de una medida adoptada por una autoridad administrativa de Bonn, con fundamento en el artículo I4, numeral I, de la Ordnungsbehördengesetz Nordrhein-Westfalen (Ley reguladora de la autoridad gubernativa del Estado federado de Renania del Norte-Westfalia). En la decisión se prohibía a la sociedad Omega "hacer posible o tolerar en su [...] establecimiento juegos que tuvieran por objeto disparar a blancos humanos mediante rayos láser u otros medios técnicos (como, por ejemplo, los rayos infrarrojos), es decir, 'jugar a matar' personas por medio de un registro de impactos”. El fundamento de la prohibición estaba en el riesgo para el orden público, pues los homicidios simulados y la banalización de la violencia a la que conducían se consideraban violatorios de los valores fundamentales preponderantes en la opinión pública. Omega, por su parte, alegaba que la prohibición encarnaba una vulneración del derecho comunitario, especialmente de la libre prestación de servicios contenida en el artículo 49 TCE, pues utilizaban equipos y tecnología provistos por la sociedad inglesa Pulsar. Según La Corte de Justicia, la restricción a la libre prestación de servicios estaba justificada en este caso porque "El Derecho comunitario no se opone a que una actividad económica que consiste en la explotación comercial de juegos de simulación de acciones homicidas sea objeto de una medida nacional de prohibición adoptada por motivos de protección del orden público debido a que esta actividad menoscaba la dignidad humana". 


\section{Las novedades 'de la época': la aparición de las nuevas tecnologías y la afirmación de un derecho europeo}

La situación de incertidumbre que, a primera vista, parecen ofrecer las concepciones de la jurisprudencia italiana y europea, hace problemático para el embrión el objetivo de nacer con dignidad, y se debe, en buena parte, a dos factores relativamente nuevos y en muchos sentidos disruptivos.

Una novedad de la época está representada, en el plano tecnológico, por los vertiginosos progresos científicos de la llamada ingeniería genética, cuyo objetivo es el embrión (en sentido deliberadamente no técnico y en relación con las técnicas de fecundación artificial -que permiten la realización de los objetivos de la paternidad social-). Paradójicamente, y pese al progreso, aún no se cuenta con datos incontestables en orden a la permanencia en vida de los embriones no implantados (o 'supernumerarios') (cfr. infra x).

Esto hace particularmente problemático, si no imposible, conciliar una protección de la dignidad del embrión con la realización de los 'deseos' de los aspirantes a padres o con objetivos legítimos de investigación científica. El artificio disfrazado (es mejor hablar de 'procreación asistida' que de 'fecundación artificial') desafía la naturaleza. Para los acérrimos defensores de esta última y de sus coordenadas institucionales seculares (desde el brocardo mater semper certa est al artículo 269 , inciso 3 c.c. "aún" vigente ${ }^{\mathrm{IO}}$ ) se trata de la apertura de la "caja de Pandora', con las nefastas consecuencias correspondientes. Para los cultores del "subjetivismo de la cultura dominante que subvierte reglas imperantes en el pasado" I se trata de la liberación del yugo opresivo de las instituciones y de la conquista de nuevas libertades individuales, capaces de transformar simples deseos en reales derechos subjetivos.

Sería una tarea del derecho, y en particular del legislador, hacer frente $e x$ professo a las innovaciones tecnológicas definiendo nuevas reglas que maticen, con razonables criterios de ponderación, los valores eventualmente subyacentes a orientaciones culturales contrastantes. Pero ante un legislador que inicialmente estaba decidido a imponer una disciplina -por así decirlo, 'autoritaria' ${ }^{\text {I2 }}$, , sin lograrlo, y durante mucho tiempo, evasivo, el derecho vivo experimenta a su vez una novedad: la afirmación de un derecho civil europeo y la consiguiente introducción, a menudo subvalorada, de principios fundamentales tendencialmente antinómicos respecto a las normas constitucionales que caracterizan el ordenamiento, con especial consideración al derecho de las personas y de la familia.

IO Esta norma sobrevivió a la Ley 2 I 9 de 20 I 2 que introdujo una reforma de las disposiciones del código civil en materia de filiación.

i I L. Lenti, "Note critiche in tema di interesse del minore", Rivista di Diritto Civile, 2016, ro9.

I La referencia es a la Ley 40 de 2004, "Normas en materia de procreación asistida". 
La antinomia de las respectivas fuentes normativas es radical, pese a las aparentes convergencias ${ }^{\mathrm{I}}$. A la 'arquitectura constitucional' de la familia diseñada por las normas -los artículos 29 a 3 I de la Constitución- inspiradas en el pensamiento personalista-solidarista e ideadas para trazar un hilo conductor que tiende a relacionar matrimonio y filiación -un unicum en el panorama de las constituciones europeas promulgadas después de la tragedia de la Segunda Guerra Mundial- se contrapone, ya en el Convenio y en la Carta de Niza, una impronta liberal e individualizadora basada en un concepto genérico y abierto de 'vida familiar', entendida como modalidad de la 'vida privada' que cualquiera puede emprender con cualquier otro, obteniendo "el respeto" (art. 7) y en el cual la relación de pareja (art. 9) y las relaciones de filiación (art. 24) se 'escinden' asumiendo una plena autonomía en su disciplina.

En última instancia, al principio de la dignidad humana se fue sobreponiendo el superprincipio de la privacy; al valor de agregación de la solidaridad, el valor individualizador de la autonomy de los (solos) sujetos involucrados.

Todo ello hace extremadamente difícil, pero necesario, experimentar un recorrido de integración de las fuentes ${ }^{\mathrm{I}}$, confiado principalmente al ahora llamado 'diálogo entre las Cortes”, con un carácter de 'presunción'15.

\section{El 'diálogo entre las Cortes'. Europa llama: matrimonio y filiación escinden sus destinos}

El itinerario de este ‘diálogo' se desarrolló, de la mano de la Corte Constitucional, a lo largo de dos trayectorias distintas, casi queriendo acoger ciegamente la tendencia europea de la 'escisión' entre matrimonio (y, en perspectiva, relación de pareja), por un lado, y filiación, por el otro.

En la primera dirección, el ‘diálogo' fue justamente eso, es decir, finalizado a una ardua búsqueda de una integración de las fuentes. La Corte Constitucional, abriéndose a los nuevos movimientos ideológicos europeos, no dejó de defender el 'núcleo duro' del ordenamiento; el Tribunal Europeo de Derechos Humanos

I 3 A una "evidente antinomia normativa" se refiere la Corte Constitucional en sentencia n. ${ }^{\circ 6}$ de 5 de junio de 2015 (en Nuova giurisprudenza civile commentata, 20 I 5, I, 933, con Opinione de G. Ferrando, Come d'autunno sugli alberi le foglie. La Legge n. $4^{\circ}$ perde anche il divieto di diagnosi preimpianto, ibíd., II, 582 ss.).

I4 "El problema no es si se puede admitir un control del Tribunal Europeo sobre un acto del Parlamento, sino sobre todo verificar cuáles consecuencias se producen cada vez que se comprueba la existencia de un contraste entre normas internas y normas del Convenio": M. MeLI, "Il divieto di fecondazione eterologa e il problema delle antinomie tra diritto interno e Convenzione europea dei diritti dell'uomo", Nuova Giurisprudenza Civile Commentata, 20 I I, II, I 6.

I 5 "Si se adopta la técnica de la decisión caso por caso prevalece la jerarquía de quienes toman la decisión, no aquella diseñada en la Carta o en los Tratados, o en las constituciones": A. GAMBaro, "Categorie del diritto privato e linguaggio delle carte dei diritti fondamentali", Rivista di Diritto Civile, 2016, I 235. 
(TEDH) se mostró evasivo, precisando en más de una oportunidad que "corresponde a la normativa interna de cada Estado la decisión de disciplinar la vida afectiva de la pareja homosexual con el matrimonio o una unión registrada" ${ }^{6}$.

Corte Constitucional ${ }^{17}$ y Tribunal de Justicia de la Unión Europea ${ }^{18}$-en sede de prejudicialidad comunitaria-, llamados de forma simultánea por parte del juez de instancia a valorar la ausencia de equiparación entre matrimonio y convivencia more uxorio, acordaban negar la subsistencia de elementos discriminatorios, a la luz del principio de no discriminación (respectivamente, arts. 2, 3 y 29 de la Constitución italiana; arts. I 2 y I 3 del Tratado Constitutivo de la Comunidad Europea). Por su parte, la Corte Constitucional reiteró que "la connotación institucional del matrimonio no se puede reducir al rango de elemento puramente formal", considerando, sin embargo, que "la relación de convivencia también asume relevancia constitucional, pero en el ámbito de la proyección de los derechos inviolables del hombre en las formaciones sociales garantizadas por el artículo 2 constitucional".

Era el año 2009. Así se confrontaba la Corte Constitucional al abordar el tema de las 'nuevas' relaciones de pareja. El año siguiente, al reconocer a las "uniones homosexuales -entendidas como convivencias estables entre dos personas del mismo sexo- el derecho fundamental de vivir libremente una condición de pareja, obteniendo [...] el reconocimiento jurídico con los correspondientes derechos y deberes" ${ }^{19}$, la Corte invocaba la intervención del legislador, dejándole la 'tarea' de determinar 'tiempo, modo y límites' de ese reconocimiento: lo que "determina la necesidad de una intervención tempestiva del legislador", agregaría cinco años después la Corte de Casación ${ }^{20}$.

Pero "se debe excluir, sin embargo, que la aspiración a ese reconocimiento -este el mensaje de la Corte a los Tribunales europeos- pueda hacerse solo mediante una equiparación de las uniones homosexuales al matrimonio": "lo decisivo [esta la conclusión] es que el artículo 9 de la Carta de Niza no impone la plena

I6 T. Auletta, "Ammissibilità nell'ordinamento vigente del matrimonio fra persone del medesimo sesso", Nuova giurisprudenza civile commentata, 2015 , I, 657 .

I 7 Corte Const., 8 de mayo de 2009, n. I40, Foro Italiano, 2010 , I, 797 s., con Osservazioni de R. Romboli y Nota de L. Cappuccio, "La convivenza 'more uxorio' tra Corte costituzionale e Corte di giustizia: uno strano caso di doppia pregiudiziale".

I 8 Tribunal de Justicia de la Unión Europea, ord. I 7 de marzo 2009, C-2 I 7/o8, Mariano vs. Inail, Foro Italiano, 2009, IV, 446, con Nota de G. Ricci.

I9 Corte Const., I 5 de abril de 20 Iо, n. I38, Foro italiano, I, I36r ss., con Nota de R. Romвoli, "Per la Corte costituzionale le coppie omosessuali sono formazioni sociali, ma non possono accedere al matrimonio", I 367 ss., de F. DAL CANTo, "La Corte costituzionale e il matrimonio omosessuale", I 369 ss., y de M. Costantino, "Individui, gruppo e coppie (libertà illusioni passatempi)", I 37 I ss.

20 Cas., 9 de febrero de 2015 , n. 2400, Nuova Giurisprudenza Civile Commentata, 20 I 5, I, 646, con "Nota di commento" de T. Auletta, "Ammissibilità nell’ordinamento vigente del matrimonio fra persone del medesimo sesso", cit., 654 ss. 
equiparación de las reglas previstas para las uniones matrimoniales entre hombre y mujer y aquella que se proponga para las uniones entre homosexuales".

Al llamado de la Corte de Casación siguió la Ley 76 de 20 de mayo de 20r6, "Reglamentación de las uniones civiles entre personas del mismo sexo y disciplina de las convivencias”. Es evidente la relación de 'dependencia' con la línea de la Corte Constitucional: a la que debe reconocerse el mérito, o esfuerzo, de haber buscado superar la barrera de la antinomia de las fuentes apuntando a una técnica de intervención que es el 'remiendo de las periferias'2 I

La ley no menciona expresamente la 'familia'22; parece partir del presupuesto implícito de que "la familia fundada en el matrimonio constituye el paradigma sistemático respecto al cual se mide la cifra de relevancia jurídica de las relaciones de pareja" ${ }^{23}$; prescinde de cualquier referencia a la filiación, pero parece postular una nueva intervención legislativa dirigida a 'remendar' en una única reforma orgánica los fragmentos normativos introducidos separadamente; se ocupa esencialmente de las 'parejas': parejas del mismo sexo unidas civilmente; parejas simplemente 'convivientes'.

Bajo esta perspectiva, el viaje del embrión hacia el objetivo del nacimiento con dignidad parecería relativamente tranquilo. El embrión concebido (o implantado) in utero goza de una 'fuerte' protección, aun ofrecida en la 'medida de lo posible'24. La medida de lo posible se configura con la ponderación entre la exigencia de proteger prioritariamente la vida y la salud de la madre: el eventual 'sacrificio' de la vida del nasciturus, en el ordenamiento italiano, es legítimo solo en los términos y con las modalidades previstos en la Ley i94 de I978, y exclusivamente en presencia de un peligro para la salud física o psíquica de la mujer, al menos según el tenor de la ley: peligro que debe ser 'serio' (art. 4). En todo caso, una cosa es cierta: la interrupción voluntaria del embarazo, a diferencia de lo que ocurre en otras latitudes (y, en particular, en la experiencia norteamericana), no se basa en un derecho constitucional a abortar, ni siquiera "ante situaciones como la descrita por el artículo $4{ }^{25}$. Se trata, justamente, de la dignidad humana del que está por nacer.

Permítaseme el reenvío a F. D. Busneldi, "Architetture costituzionali, frammenti europei, incursioni giurisprudenziali, rammendi legislativi", en M. GoRGONI (ed.), Unioni civili e convivenze di fatto (L. 20 maggio 20I6, n. 76), Santarcangelo di Romagna, 20I6, xxi ss.; y a F. D. Busnelli, "Il diritto della famiglia di fronte al problema della difficile integrazione delle fonti", Rivista di Diritto Civile, vol. 62, n. ${ }^{\circ}$ 6, 2016, I447-1478.

22 Aparecen solo referencias esporádicas a 'vida familiar' (inc. I2), 'núcleo familiar' (inc. 45), casa familiar (inc. 60), 'familiares' (inc. 39).

23 R. Senigaglia, Status filiationis e dimensione relazionale dei rapporti di famiglia, Napoli, 2013, 30.

24 Sobre el concepto de 'fuerte' protección al embrión y sobre los límites correspondientes se reenvía F. D. Busnelli, "Statuto giuridico dell'embrione", en proceso de publicación en la Enciclopedia di Bioetica e di Scienza giuridica.

25 T. Padovani, "Commento dell'art. ig", en C. M. Bianca y F. D. Busnelli, "Commentario della Legge 22 maggio 1978, n. 194”, Nuove Leggi Civili Commentate, I978, I 705. 


\section{La Corte Constitucional responde: la 'intervención demoledora' de la Ley 40 de 2004}

El 2009 es también el año en el que la Coste Constitucional establece las premisas de una segunda trayectoria, proclive a recibir la orientación europea en materia de filiación. Es el año de la primera 'intervención demoledora' de la Corte Constitucional ${ }^{26}$ en relación con el andamiaje construido por la Ley 40 de 20I4, para 'blindar' una prohibición general de crioconservación y de supresión de embriones mediante la imposición de un límite legal a las técnicas de reproducción asistida de tipo homólogo -las únicas permitidas en ese entoncesconsistente en la prohibición de crear un número de embriones superior a tres embriones (considerado el número estrictamente necesario) disponibles para "un único y simultáneo implante" (art. I4, inc. 3).

El problema de legitimidad constitucional, en contraste con los artículos constitucionales 3 y 32 , era exclusivamente un problema de derecho interno y no socavaba de forma directa la 'arquitectura constitucional' de la familia. Así lo afrontó la Corte Constitucional: que, entre otras cosas, al declarar constitucionalmente ilegítimo el vínculo legal del único triple implante (porque potencialmente lesivo de la salud de la madre y del feto), y al confiar a la autonomía y a la responsabilidad del médico el deber de no crear "un número de embriones superior al estrictamente necesario", no pudo eximirse de la necesidad de incluir "una derogación al principio general de prohibición de crioconservación” recurriendo "a la técnica de congelamiento de embriones producidos pero no implantados por decisión médica”, buscando respetar la exigencia de realizar la transferencia in utero "apenas sea posible" pero "sin perjuicio para la salud de la mujer".

Sin embargo, la 'fuerte' protección del embrión se vio necesariamente minada. La misma Corte Constitucional admitió la consecuencia de "un debilitamiento de la tutela del embrión" en virtud de la necesidad de identificar aquello que, de forma ambigua, se definió "una justa ponderación con la tutela de las exigencias de la procreación".

La grieta se profundizó y se extendió rápidamente.

En el primer sentido, pesó como una roca el silencio del legislador sobre la suerte de los embriones crioconservados. Tal como hizo una "Comisión de estudio sobre los embriones crioconservados" ${ }^{27}$ el día siguiente a la publicación de la sentencia, insistir en la conservación a tiempo indeterminado especulando que "el progreso de la investigación científica permitirá identificar criterios y

26 Corte Const., 8 de mayo de 2009 , n. I 5 I, en Nuova Giurisprudenza Civile Commentata, 2009, I, I 23 ss., con Nota di commento de G. Ferrando, Fecondazione in vitro e diagnosi preimpianto dopo la decisione della Corte costituzionale, ivi, II, 52 I ss.

27 La referencia es a la "Relación final" aprobada por mayoría el 8 de enero de 20 io por la "Comisión de estudio de los embriones crioconservados en los centros de P.м.A.”, nombrada por decreto del Ministerio de la Salud y de las Políticas Sociales del 25 de junio de 2009. 
metodologías para diagnosticar la muerte o, en todo caso, la pérdida de vitalidad de los embriones crioconservados" reveló rápidamente ser aquello que era: una simple utopía.

En el segundo sentido, desde Europa soplaba, siempre más impetuoso, el viento de la perentoria apertura a las técnicas de fecundación artificial heterólogas. La recordada "tutela de las exigencias de la procreación” asumía en Estrasburgo, solo un año después (2010), la semblanza de un derecho "a satisfacer el deseo de un hijo": la garantía de un derecho en ese sentido, adoptada como "faceta particularmente importante" por el TEDH para afirmar, con sentencia de la Sección I, la contrariedad de la normativa austriaca al Convenio en materia de fecundación heteróloga, acusada de desconocer parcialmente ese derecho, y al mismo tiempo para señalar polémicamente a los únicos Estados (Italia, Lituania y Turquía) que aún preveían una prohibición absoluta de acceso a dichas técnicas ${ }^{28}$.

La decisión no pasó inobservada e indujo a tres jueces de instancia ${ }^{29}$ a asumirla -totalmente (Florencia) o parcialmente (Catania y Milán)- como argumento determinante para plantear la cuestión de legitimidad constitucional $3^{\circ}$ de la prohibición de la fecundación heteróloga por el artículo 4, inciso 3 de la Ley 40.

\section{El viraje hacia la 'cultura del deseo'}

En el arco de solo un año la situación cambió de forma inesperada. En 20 i i la Gran Sala revirtió aquella decisión, afirmando el principio según el cual "debe reconocerse a cada Estado un amplio margen de apreciación cuando no exista consenso entre los Estados partes"3 3 .

Al formular el recurso a la Corte Constitucional, dos de los jueces a los cuales, en el entretanto, una ordenanza de la Corte había restituido los recursos

28 Tedh, sección I, I de abril de 20 Iо, S.H. et alii c. Austria, en Nuova Giurisprudenza Civile Commentata, 20 IO, I, IO82 ss., con Nota di commento de B. Liberali, "La sentenza della Corte europea dei diritti dell'uomo in tema di procreazione medicalmente assistita di tipo eterologo", ivi, II, 556 ss.

29 Trib. Firenze, 6 de septiembre de 20 Iо; Trib. Catania, 2 I de octubre de 20 Io; Trib. Milano, 2 de febrero de 20 I I.

30 Nota de trad.: la questione di legittimità costituzionale (art. I 37 de la Constitución italiana) se refiere a un incidente procesal, que se tramita a instancia de parte o de oficio, mediante el cual se somete a consideración de la Corte Constitucional la eventual inconstitucionalidad de una ley, por vicios formales o materiales, o de actos con fuerza de ley (decretos ley y decretos legislativos); es decir, no procede respecto de las normas consuetudinarias, de derecho internacional privado o de derecho comunitario. El proceso se suspende hasta cuando la Corte Constitucional se pronuncie: mediante sentencia de rechazo, con efectos inter partes, o con sentencia de aceptación, con efectos erga omnes y de anulación del acto impugnado.

3 I Tedh, Gran Sala, 3 de noviembre de 20 I I, n. 578г 3/oo, S.H. et alii c. Austria, en Nuova Giurisprudenza Civile Commentata, 2012, I, 224 ss., con "Nota di commento" de C. Murgo, "La Grande chambre decide sulla fecondazione eterologa e la rimette all'apprezzamento degli Stati contraenti", 233 ss. 
para una necesaria reconsideración del argumento 'europeo', omitieron invocar dicho argumento para proponer nuevamente la cuestión de legitimidad constitucional como una cuestión de puro derecho interno ${ }^{32}$.

La Corte Constitucional se adecuó mediante una decisión de $2014^{[33]}$, e -incredibile dictu!- en lugar de considerar la señal enviada por la Gran Sala del TEDH para explorar los amplios ("wide”) márgenes de apreciación con miras a superar de modo razonable las tendenciales antinomias normativas (siguiendo la 'política' trazada por la sentencia n. ${ }^{\circ}$ I 38 de 20 Io: cfr. supra III), se exhibió en una carrera desenfrenada hacia la liberalización, superando d'emblée la cautela y los límites surgidos en Estrasburgo.

A terrific judgement, ¡ en los dos sentidos opuestos del término!

Devastador aparece a los ojos de aquellos (quorum ego) que miran con evidente aflicción a una alta institución que, llamada a defender la Constitución, ignora uno de los núcleos estructurales más significativos y peculiares (los artículos 29-3 I [nota de trad.: referidos a la familia]), omitiendo argumentar, dada la relevancia de ese unicum, la sostenibilidad de un margen de apreciación de la norma sub iudice -que se inspira en él-para contradecir una controvertida línea europea tendencialmente antinómica.

De otra parte, resulta desconcertante el llamado a un principio de específico valor constitucional - la llamada autodeterminación, a la cual la Corte Constitucional se ha referido en el pasado "para otros fines y en un ámbito distinto"34_ con el objetivo de trasplantar al ordenamiento italiano el genérico 'respeto a la vida privada y familiar' consagrado en el artículo 8 del Convenio (y en el artículo 7 de la Carta de Niza). En fin, es visiblemente forzada la referencia a la institución tradicional de la adopción, arbitrariamente desanclada del artículo 30 constitucional (norma simplemente "olvidada" 35 ) para avalar una genérica parentalidad social motivada por el deseo de crear artificialmente un hijo.

Por el contrario, "extraordinariamente relevante" resultó la sentencia para quien le otorga a ella el mérito de valorizar el "diálogo con Estrasburgo" proponiendo "una lectura de la Constitución pasada por el tamiz del Convenio", al punto de decretar la superación de "una particular concepción ética de la familia y de la relación de pareja que puede ser respetable [sic], pero que no tiene ningún fundamento constitucional y que no puede ser impuesta por ley a quien no la comparte" 36 .

32 Trib. Firenze, 29 de marzo de 2013; Trib. Catania, I3 de abril de 2013.

33 Corte const., Io de junio de 2014, n. I62, en Nuova Giurisprudenza Civile Commentata, 2014, I, 802 ss., con "Opinione" de G. Ferrando, "Autonomia delle persone e intervento pubblico nella riproduzione assistita. Illegittimo il divieto di fecondazione eterologa", ivi, II, 393 ss.

34 Lo recuerda puntualmente la Corte Const., io de junio de 2014, n. I62, cit., n. 6.

35 C. Castronovo, "Fecondazione eterologa: il paso (falso) della Corte costituzionale", Europa e Diritto Privato, 2014, I 23.

36 G. Ferrando, Autonomia delle persone, cit. 404, y citaciones en nota 50. 
En este punto, una cosa es cierta: la nueva 'intervención demoledora' de la Ley 40, a diferencia de la anterior, no se limita a intervenir respecto de los vínculos normativos 'autoritarios' de actuación de las técnicas de fecundación artificial allí reguladas, "manteniendo a salvo el principio" que inspira la ley37; sino que lo incluye directamente, superando la engañosa premisa "de que la Técnica de Reproducción Humana Asistida (TRHA) de tipo heterólogo es una species del genus" ${ }^{8}$.

Este es un habilidoso 'caballo de Troya' para hacer entrar la 'cultura del deseo' dentro de los muros de la 'arquitectura constitucional' de la familia. No se puede -comenta la doctrina que aplaude la sentencia en estudio- "sacrificar la libertad de las personas que quieran recurrir a las técnicas heterólogas [...] haciendo honor a la llamada 'naturalidad' de la procreación"39. Conspira en ese sentido -se agrega- la Ley 2 I9 de 20 I 2 (cfr. supra nota Io) que, unificando el estado jurídico de los hijos, "lleva a término el proceso de 'separación' entre matrimonio y filiación, de modo que la condición jurídica de los hijos resulta protegida como valor autónomo"40.

Pero, frente a esta nueva 'cultura' ¿en qué consiste el valor autónomo que se atribuye a la 'condición jurídica' de los hijos y, en particular, de los embriones?

La sentencia de la Gran Sala del TEDH revela la consideración de las preocupaciones manifestadas por el gobierno austriaco sobre las “complejas cuestiones sociales y morales que involucran la dignidad humana, el bienestar de los hijos concebidos de ese modo y la prevención de los inconvenientes o de los posibles abusos", compartiendo "el cuidado y la circunspección con los cuales el legislador austriaco buscó conciliar las realidades sociales con sus posiciones de principio en relación con esta materia" ${ }^{1}$. Más en general, la Corte de Estrasburgo no ha dejado de afirmar que "las preocupaciones atinentes a consideraciones de orden moral o a la aceptabilidad social de las técnicas en cuestión deben ser tomadas en serio", aun si ellas "no sirvieran, por sí solas, para justificar una prohibición total"; y que, en particular, la utilización de la fecundación in vitro "sigue suscitando delicados interrogantes" que impiden la formación de "una clara comunidad de visiones entre los Estados miembros" ${ }^{2}$.

La sentencia de la Corte Constitucional, más allá de plantearse problemas similares, se preocupa prioritariamente por la 'salud de la pareja', sobre la cual

Así Corte Const., 8 de mayo de 2009, n. I 5 I, cit. n. 6.I.

$3^{8}$ Así Corte Const., I 8 de junio de 2014 , n. I62, cit., n. I I. I.

39 G. Ferrando, Autonomia delle persone, cit. 404.

40 Ibid., p. 406.

4I TEDH, 3 de noviembre de 20 I I, cit. n. I I3. La ley austriaca prohíbe acudir a la trHa de tipo heterólogo, con la excepción de aquella practicada mediante la donación de gametos masculinos en el procedimiento llamado in vivo.

Ibíd., nn. 96 y гоo. 
-insiste la Corte- "puede incidir negativamente, aun de forma relevante, la imposibilidad [...] del uso de la TRHA de tipo heterólogo. [T]ambién con referencia a la verificación de la existencia de una lesión del derecho a la salud psíquica"43. En relación con la tutela de "otros valores constitucionales involucrados", la sentencia es categórica al afirmar que "las exigencias de tutela del nacido" -a quien "se referirían eminentemente las problemáticas"- no plantean cuestiones "nuevas" y "deben considerarse garantizadas congruamente" por las mismas normas dictadas para la fecundación homóloga y por aquellas vigentes en materia de adopción44, bajo el entendido del principio general según el cual no le incumbe a la Corte "eliminar las eventuales lagunas que no pueden ser colmadas mediante los instrumentos de interpretación ordinarios".

Esta tarea, como se sabe, "corresponde a la sabiduría del legislador" 45 , de un legislador inerte, entre otras cosas: a la cual, en últimas, sigue vinculada la tutela de la dignidad del embrión.

Por su parte, la Corte Constitucional se limita a asegurar, con "alegre superficialidad" 46 , que "la TRHA de tipo heterólogo busca favorecer la vida" 47.

\section{El desembarco en la 'cultura del descarte'}

De la 'cultura del deseo' a la 'cultura del descarte' $4^{8}$ hay un solo paso; y lo ha dado rápidamente la Corte Constitucional49 que, animada por la 'vocación aditiva' de la sentencia apenas comentada, consideró permitido, e incluso oportuno, uniformarse a una sentencia del TEDH que había condenado a Italia por la violación del 'usual' artículo 8 del Convenio, afirmando que lesiona el "derecho al respeto de la vida privada y familiar" la norma (art. 4, inc. I) de la 'usual' Ley 40 que prohíbe a las parejas fértiles portadoras de enfermedades genéticas acceder a la TRHA y al diagnóstico genético preimplantacional (DGP) $5^{\circ}$.

43 Corte Const., io de junio de 2014 , n. I62, cit., n. 7 .

44 Ibíd., n. I3.

45 Ibíd., n. I I.

46 "Ya hemos tenido mucho tiempo de degradación moral, burlándonos de la ética [...], y llegó la hora de advertir que esa alegre superficialidad nos ha servido de poco": Francisco, Laudato si. Carta encíclica sobre el cuidado de la casa común, Tipografía Vaticana, Ciudad del Vaticano, 24 de mayo de 2015 , n. 229, disponible en: http://w2.vatican.va/content/francesco/es/encyclicals/ documents/papa-francesco_20150524_enciclica-laudato-si.html

47 Corte Const., Io de junio de 2014 , n. I62, cit., n. 9.

48 Francisco, Laudato si', cit., n. I6.

49 Corte Const., 5 de junio de 20 I $_{5}$, n. 96, cit., con "Opinione" de G. Ferrando, "Come d'autunno sugli alberi le foglie", cit., 582 ss.

50 TEDh, 28 de agosto de 20 г 2, n. 54270/ro, Costa y Pavan c. Italia, en Nuova Giurisprudenza Civile Commentata, 2013, I, 66 ss., con "Nota di commento" de C. Pardini, "La diagnosi preimpianto al vaglio della Corte europea dei diritti dell'uomo: influenza delle pronunce nel panorama ita- 
A la Corte Constitucional no le faltaría ocasión para desatender la frágil argumentación que fundamenta la decisión del Tribunal de Estrasburgo: ella imputa arbitrariamente al sistema italiano una falta de coherencia, consistente -en su criterio- en prohibir a los solicitantes el derecho a limitar la implantación a solo los embriones 'sanos' y, al mismo tiempo, en autorizarlos a abortar un feto afectado por la enfermedad. Con la consecuencia de que confiere de forma perversa a la disciplina del aborto una naturaleza eugenésica "claramente no consentida por la Ley I94 de I978" $5^{\mathrm{I}} 5^{52}$, e ignora que la legitimación para la interrupción voluntaria del embarazo está reservada a la mujer gestante y no a la pareja.

La Corte, frente a la "evidente antinomia normativa" 53 entre el ordenamiento italiano y la jurisprudencia europea, en vez de empeñarse para ofrecer una posible solución que concilie las exigencias opuestas ${ }^{54}$, ha preferido alinearse con esta última, renovando la solución con el reconocimiento de una violación del artículo 32 constitucional "por el irrespeto del derecho a la salud de la mujer portadora (ella misma o el otro sujeto de la pareja) de la enfermedad", y no identificando, "en términos de ponderación, una exigencia de tutela del nasciturus" por cuanto - borresco referens- este último "estaría, en todo caso, expuesto al aborto" 55 .

Aquí al embrión se le niega el objetivo de nacer con dignidad en cuanto destinado a ser suprimido [...] ¡con el visto bueno de la Corte Constitucional!

liano", p. 8 o ss., y el Saggio de G. Ferrando, "Le diagnosi preimpianto, dunque, sono ammissibili", ivi, II, 20 ss.

5 I R. Ромiato, “Diagnosi preimpianto e tutela dell'embrione: un equilibrio ancora precario”, $E u$ ropa e Diritto Privato, 2016, 236.

52 Nota de trad.: la Ley I 94 de I 978 , que contiene las normas para la tutela social de la maternidad y sobre la interrupción voluntaria del embarazo, despenalizó y disciplinó las modalidades para acceder al aborto. De acuerdo con la ley, se permite interrumpir el embarazo dentro de los primeros noventa (90) días de embarazo, a la mujer "que acuse circunstancias que, de continuar con el embarazo, el parto o la maternidad, comportarían un serio peligro para su salud psicofísica, en relación con su estado de salud o sus condiciones económicas, o sociales, o familiares, o con las circunstancias en que ocurrió la concepción, o con la previsión de anomalías o malformaciones del concebido" (art. 4); o después de noventa (90) días, "cuando el embarazo o el parto comporten grave peligro para la vida de la mujer" o "se verifiquen procesos patológicos, entre los que están aquellos relativos a relevantes anomalías o malformaciones del nasciturus, que determinen un grave peligro para la salud psicofísica de la mujer" (art. 6); no siendo posible que el padre del concebido pueda interferir con la decisión de la mujer (art. 5).

53 TEDH, 28 de agosto de 2012 , cit., n. 9 .

54 Para una "formulación alternativa", cfr. Ромінто, Diagnosi preimpianto e tutela dell'embrione, cit., $245 \mathrm{~s}$.

55 Corte Const., 5 de junio de 2015 , n. 96 , cit., n. 9 . 


\section{Alea iacta est ${ }^{5}$}

La Corte Constitucional, con sus sentencias 'aditivas', ha llevado más allá de lo posible su intento 'demoledor', terminando por revertir de forma subrepticia "el modelo previsto originalmente por el legislador", que "se fundaba en la advertida necesidad de evitar la práctica [...] de la crioconservación de embriones supernumerarios" 57 . Es decir, la Corte evidentemente decidió asignar una relevancia prioritaria a la 'cultura del deseo' y a aquella del 'descarte', haciendo inevitable una decisión consiguiente: aquella consistente en determinar la suerte que ha de reservarse a los embriones supernumerarios, cuyo número "resulta virtualmente ampliado' y verosímilmente "destinado a la destrucción" -se lee en la ordenanza que ha elevado la cuestión de legitimidad constitucional del artículo I3 de la Ley $4{ }^{\left[{ }^{[8]}\right]}$. Es -admite la Corte- "aquella que alguien ha definido como una 'elección trágica' entre el respeto por el principio de la vida (que acompaña al embrión aun afectado de una patología) y las exigencias de la investigación científica" 59 .

De este modo llegamos a la última etapa de una especie de yincana organizada por la Corte Constitucional en relación con los tribunales europeos. Ella ha descuidado deliberadamente la señal del Tribunal de Estrasburgo de disponerse a la confrontación, abriendo de par en par las puertas a la fecundación artificial de tipo heterólogo ${ }^{60}$-en oposición al dictado legislativo y sin 'imposición' por parte de Europa-; se apoyó ciegamente en una sentencia infundada del mismo tribunal $^{6 \mathrm{r}}$ al tachar con la ilegitimidad constitucional el ordenamiento italiano, sosteniendo, contra la evidencia, que el mismo permitiría "perseguir el objetivo de procrear un hijo no afectado por una patología hereditaria de la que la pareja es portadora, mediante la, innegablemente más traumática, modalidad de la interrupción voluntaria $[\ldots]$ de embarazos naturales" ${ }^{\prime 2}$. En fin, consciente de las

56 Nota de trad.: el uso de esta expresión lo atribuye Suetonio, en La vida de los doce césares, Vida del divino César, libro I, \$33, a Julio César luego de que decidiera pasar el Rubicón (cfr. infra nota 77). El sentido del uso común puede ser el de "la suerte está echada", para referirse a un punto de no retorno, a la toma de una decisión o un paso irrevocable.

57 G. De Rosa, "Scienza, tecnica e diritto in recenti applicazioni giudiziale della disciplina in materia di procreazione medicalmente assistita", Nuova Giurisprudenza Civile Commentata, 2013, I, 6ri3.

$5^{8}$ Trib. Firenze, I 2 de diciembre de 201 2, Nuova Giurisprudenza Civile Commentata, 201 3, I, 598.

59 Corte Const. I3 de abril de 20 r6, n. 84, cit., n. I r. En el 'alguien' podría reconocerse el suscrito, pues desde hace tiempo había señalado como "indudablemente 'trágica', en un sistema que ha optado por la subjetividad del concebido, la elección que se proyecta aquí, de iure condendo": F. D. Busnelli, "Cosa resta della legge 4o? Il paradosso della soggettività del concepito", Rivista di Diritto Civile, 20 I I, II, 467.

60 Corte Const. Io de junio de 2014, n. I62, cit.

6I TEDH, 28 de agosto de 2012 , n. 54270/ro, cit.

62 Corte Const., 5 de junio de 2015 , n. 96 , cit., n. 9 . 
incertezas y de las deformidades que connotan las decisiones de los tribunales europeos (de Estrasburgo y de Luxemburgo) en relación con la naturaleza jurídica del embrión no implantado y a su posible destinación a la investigación científica (cfr. supra I), e influida por la desconcertante ambigüedad de la más reciente "no-decisión" del caso Parrillo c. Italia ${ }^{63}{ }^{64}$, decide ahora 'sustraerse' a un control de "una elección a tal punto discrecional" ${ }_{5}$.

\section{VIII. "Tu l'as voulu!"}

Esto darían ganas de exclamar instintivamente, inspirados a la célebre "farsa" de Molière ${ }^{66}$.

Pero la combinación sería claramente falaz. En primer lugar, sería insensato, o al menos irreflexivo, paragonar el resultado de la intervención demoledora de la Corte Constitucional al humillante efecto de las ambiciosas iniciativas del desprevenido George Dandin -vous avez justement ce que vous méritez ${ }^{6} 7$ - recientemente evocadas en Francia para describir en tono de comedia las desventuras políticas de François Hollande.

En realidad, la Corte no pretende "cerrar el círculo con una inversión interpretativa" en una renovada "deferencia a la subjetividad del embrión que constituye el aspecto más oscuro de la Ley 40 de 2004 "68.

En otras palabras, su decisión no busca reconsiderar la vocación demoledora; más bien sugiere la solución que cree más idónea para obtener el resultado final.

63 Tedh, Gran Sala, 27 de agosto de 20 I 5, n. 4670/ i I, Parrillo c. Italia, en Foro Italiano, 20 I 5, Iv, 453 ss., con "Nota" de G. Casaburi, "Ricerche embrionali: una occasione perduta dalla Corte europea".

64 Nota de trad.: en el caso, una mujer, que se había sometido a un tratamiento de fecundación asistida del que resultaron fecundados cinco embriones, decidió renunciar al implante de los embriones debido a la muerte de su compañero en el atentado a la base italiana de Nāşiriya (Irak) el I 2 de noviembre de 2003. La mujer solicitó la donación de los embriones crioconservados para investigación, solicitud que fue negada por expresa prohibición del artículo I 3 de la Ley 40 de 2004. El recurso ante el TEDH, por supuesta violación del artículo 8 del cEDH, no obtuvo respuesta positiva por parte del Tribunal, que consideró que, no tratándose de un problema ligado a la decisión de convertirse en madre, el derecho a donar los embriones para destinarlos a investigación científica no hace parte de los derechos fundamentales protegidos por el artículo 8, por lo que la prohibición de la Ley 40 no excedía el amplio margen de discrecionalidad del Estado en el caso analizado.

65 Corte Const., I 3 de abril de 20 r6, n. 84, cit., n. I I.

66 Se hace referencia a la expresión “vous l'avez voulu, George Dandin”, de la comedia de Molière "George Dandin ou le Mari confondu" (г668).

67 Acte I, scene 9.

68 En cambio, así G. Casaburi, La corte costituzionale e la l. 4o/o4: un ritorno all'ordine, cit., I 5 I 9. 
$\mathrm{Al}$ respecto se observó, justamente, que la Corte Constitucional "cuando quiso, no dudó en adoptar sentencias de aceptación, aun sabiendo que creaba lagunas"69.

La Corte Constitucional cambia de estrategia e invoca la intervención del legislador, no por un impulso de "revitalización de la moribunda Ley 40 de 2004 "70, ni por una mera "valoración de oportunidades"71, cuanto para contrastar la introducción de una importante salvedad, "originada en un procedimiento penal" ${ }^{2}$, que desembocó en una sentencia que -completando la sentencia n. ${ }^{\circ}$ 96/2015- confirma la legitimidad de la norma (art. I4, inc. I) que prohíbe la supresión de embriones, también -y este es el quid novi- de aquellos "que luego del DGP resulten afectados por una grave enfermedad genética", pero sanciona la ilegitimidad constitucional de la norma (art. I 3, incs. 3, lit. b, y 4 de la Ley 40 de 2004) que "prohíbe, penalmente, la conducta selectiva del médico dirigida exclusivamente a evitar la implantación de un embrión enfermo en el útero"73.

Conviene preguntarse de qué se trata esta solución: no tratándose de "[u]n exceso de celo de la Corte Constitucional, en contraste con el principio de taxatividad de la norma penal" 74 o de una precisión dirigida a aclarar que la eventual discapacidad de un embrión no justifica "per se un tratamiento desfavorable en comparación con el de los embriones sanos"75, ¿puede querer decir sí que "la única suerte posible para los embriones seguramente no destinados a la implantación, en cuanto afectados por graves patologías, sigue siendo la crioconservación" 76 ?

Para la Corte Constitucional, que se atiene a esta última interpretación, a decir verdad, la más descontada, llegó el momento de cruzar el Rubicón77: esta iniciativa corresponde -rectius, le incumbe- al legislador.

69 Ibíd., 520.

70 Ibíd., I 5 I 8 .

7 I Corte Const., I3 de abril de 2016 , n. 84, cit., n. I I.

72 A. VALLINI, "Gli ultimi fantasmi della legge '40: inconstituzionale il (supposto) reato di selezione preimpianto", Diritto penale e processo, 2016, 74, en nota a Corte const., I I de noviembre de 2005 , n. 229.

73 Corte Const., I I de noviembre de 2005, n. 229, cit.

74 A. VAllini, Gli ultimi fantasmi, cit., 74 y 76.

75 Corte Const., I 3 de abril de 2016 , n. 84, cit., n. 3 .

76 C. PARdini, "Libertà di ricerca scientifica e tutela dell'embrione", Nuova Giurisprudenza Civile Commentata, 2016, II, 798.

77 Nota de trad.: el autor utiliza la expresión cruzar el Rubicón para señalar que es el momento para que la Corte se disponga, irrevocablemente, a cumplir una acción definitiva. La frase cruzar el Rubicón evoca el momento histórico (año 49 a.C.) en el que Julio César decidió cruzar el río Rubicón con su ejército. Este curso de agua marcaba el confín entre la Galia Cisalpina y el territorio cívico romano, por lo que ningún general podía cruzarlo en armas sin autorización expresa del senado; hacerlo correspondía a un acto de invasión militar. Fue así que empezó la segunda guerra civil romana. Cfr. Geraci, G. y Marcone, A., Storia romana, Milano, Mondadori, 4. ${ }^{\text {a }}$ ed., 2016, I49. 


\section{Invocar una intervención del legislador no es una novedad}

Ya lo decía la Corte Constitucional (sentencia n. ${ }^{\circ}$ I 5 I de 2009) al constatar "la necesidad de recurrir a la técnica de congelamiento respecto de los embriones producidos, pero no implantados por decisión médica".

Lo insinuaba igualmente, como se vio (sentencia n. ${ }^{\circ}$ I62 de 2014), para exonerarse de responsabilidad por el posible 'vacío normativo' provocado por la superación de la prohibición de fecundación heteróloga.

Recurrió a él (sentencia n. ${ }^{\circ} 96$ de 2015) al advertir que era "tarea del legislador introducir disposiciones especiales con miras a la deseable identificación [...] de las patologías que puedan justificar el acceso a las TRHA de parejas fértiles [...] (también a efectos del sometimiento preliminar al diagnóstico preimplantacional)".

Pero todas eran hipótesis en las que la Corte estaba lejos de sustraerse a su propio control: el legislador era invocado con funciones, por así decirlo, 'auxiliares' en relación con el objetivo de resolver problemáticas consiguientes al decisum. Y el legislador nunca respondió al llamado.

Aquí la situación es distinta. El llamado al legislador es una invitación a decidir el quehacer. Pero no se trata simplemente, más allá de las apariencias, de resolver la cuestión de legitimidad constitucional propuesta desde el año 20 I 2 por el Tribunal de Florencia: "la perenne cuestión [...] inherente a la ponderación constitucionalmente razonable entre tutela del embrión e interés en la investigación científica para proteger la salud (individual y colectiva)" 78 , y considerada en el año 2016 por la Corte Constitucional todavía "nueva, y ni siquiera implícitamente considerada por sus providencias precedentes" 79 (aunque, en realidad, incidentalmente rozada por la sentencia n. ${ }^{\circ} 229$ de 2015 ).

La 'trágica elección' evocada por la Corte Constitucional, guste o no, fue hecha un paso tras otro por la misma Corte, con su recorrido 'demoledor' de la Ley 40. La 'cultura del deseo' y la 'cultura del descarte' ya han tomado la ventaja frente al carácter absoluto del 'principio de la vida' del embrión, yendo mucho más allá de un simple 'desvanecimiento' de la tutela respectiva. La alternativa que ahora proyecta la Corte Constitucional entre 'dos frentes opuestos' de la mencionada elección tuvo solo un significado de reconocimiento de las contrastantes tesis "sostenidas en distintos escenarios, doctrinales y científicos"

En últimas, la Corte no es 'neutral'; no le pide al legislador, más allá de la formulación literal de la cuestión, una elección entre un "non liquet" (o mejor, un silencio que confirma el statu quo) y una reconsideración legislativa de la solución al problema inicial. Quiere esta última. Le pide al legislador "traducir en el plano 
normativo la ponderación entre valores fundamentales en conflicto, teniendo en cuenta la orientación e instancia que aprecie que están en mayor medida, en el momento dado, radicadas en la consciencia social”; pide, más específicamente, responder al problema -suscitado por el caso concreto- de "una diversa ponderación de los valores en conflicto, en la dirección, deseada por el remitente, de una mayor apertura a las exigencias de la colectividad en relación con las perspectivas de la investigación científica" ${ }^{\text {I }}$.

\section{Cruzar el Rubicón}

Cruzar el Rubicón significa, entonces, plantear de forma preliminar un problema de amplitud dramáticamente más general, que parte de una necesaria reconsideración de la "realidad concreta de la existencia de miles de embriones destinados irremediablemente al deterioro en los centros italianos de procreación asistida" 82 .

Quid agendum est? Este sí es un problema que solo el legislador está legitimado a afrontar, atrapado entre una adquisición jurisprudencial vinculante y el respeto de principios constitucionalmente sancionados.

La adquisición consiste en la reconocida legitimidad de la formación, y ampliación, de una real categoría de embriones (llamados supernumerarios) a los cuales se impide alcanzar la meta del nacimiento; y de su distinción en subcategorías de embriones 'sanos' y 'enfermos'.

Los principios de referencia consisten en la salvaguardia de la dignidad humana del embrión y en la consiguiente exigencia de no discriminación.

A la luz del primer principio se deriva un dramático interrogante: junto al objetivo del nacimiento con dignidad, ¿puede considerarse, para los embriones supernumerarios, la meta de 'morir' con dignidad?

La circunstancia de que la investigación científica no permita todavía diagnosticar "la muerte o, en todo caso, la pérdida de vitalidad de los embriones crioconservados" no debe impedirle al legislador rebelarse a la "paradoja, legalmente inevitable [!], de una crioconservación que podría no tener nunca un fin"83.

\section{La cuestión de la 'muerte'}

Entre filósofos y juristas mucho se ha discutido sobre la "cuestión de la muerte de los seres humanos", sin alcanzar nunca conclusiones consensuales: "quien interviene en tales cuestiones creando expectativas de certeza absoluta -se ha

8 I Ibíd., n. I I.

82 C. PARDInI, Libertà di ricerca scientifica e tutela dell'embrione, cit., 796.

83 "Relación final" de la Comisión de Estudio de los Embriones Crioconservados, cit. 
escrito $^{84}$ - lo hace porque está confundido o porque quiere contaminar una discusión pacata sobre una cuestión tan dramática como la de la vida humana".

Entonces, si no se puede pretender que "la ciencia defina, de manera más o menos demostrativa, nociones como 'muerte', 'muerte de un ser humano', 'muerte de una persona' [es necesario] reconocer una prioridad de las cuestiones éticas respecto a los datos científicos" $" 5$.

La "cuestión de la muerte de los seres humanos" está referida comúnmente a los sujetos ya nacidos. $\mathrm{Y}$ es cierto que "los padres, los médicos y los científicos [son] indiferentes a la muerte del embrión no anidado" 86 . Sin embargo, la crioconservación de un embrión que no se puede implantar in utero y reducido a una “condición de eterna suspensión en vidrio y hielo" 87 es sinónimo de 'muerte', de muerte sin dignidad.

¿Reconocer una prioridad de las cuestiones éticas puede tolerar 'el escándalo' de "vidas humanas diversamente importantes"? ${ }^{88}$ ¿De seres humanos que, así como tendrían 'menos derecho' a la vida ${ }^{89}$, tendrían también 'menos derecho' a morir con dignidad?

Al legislador, que ha proveído con leyes y reglamentos mientras se verificaban muertes de sujetos ya nacidos -buscando interpretar el consenso de la comunidad científica, sin lograrlo del todo ${ }^{9}-$, se le pide ahora que verifique si a la ilegitimidad -por confirmar- de la 'supresión de embriones' puede corresponder la introducción de una expresa previsión del derecho de los embriones, 'sacrificados' en homenaje a la 'cultura del deseo' y a la 'cultura del descarte', de 'morir con dignidad'.

En una perspectiva confiada al legislador, la Corte Constitucional se refiere al 'sacrificio' del embrión, con lo cual configura un evento que podría 'justificar'

84 E. Lecaldano, "La questione della morte. Definizione tra etica e filosofia", en S. Rodotà y P. Zatti (dirs.), Trattato di biodiritto, Il governo del corpo, editado por S. Canestrari, G. Ferrando, C.M. Mazzoni, S. Rodotà, P. Zatti, t. il, Milano, 201 I , 2025 ss., 2032.

85 Ibíd., 229 s.: "también Defanti [en Soglie. Medicina e fine della vita, Torino, 2007] desplaza la discusión sobre la muerte al plano ético, siguiendo los pasos de Peter Singer [...]; pero las conclusiones son del todo diversas a aquellas alcanzadas por los defensores de la doctrina católica". En todo caso, es cierto que "la necesidad de determinar con certeza legal -aun a costa de realizar una redefinición legal de la muerte considerando una fictio iuris- el evento de la muerte se vuelve una exigencia tanto científica como social y ética": M. Di MAsI, "Definire la morte; tra diritto e biopolitica", en F. Cortese y M. Tomasi (eds.), Le definizioni nel diritto. Atti delle giornate di studio 30-3I ottobre 2015, Trento, 2016, $276 \mathrm{~s}$.

86 L. Lombardi Vallauri, "L'embrione e le vite diversamente importanti”, en S. Rodotà (ed.), Questioni di bioetica, Roma-Bari, r993, 36r ss.

87 D. Carusi, "In vita, 'in vitro', in potenza. Verso una donazione dell'embrione soprannumerario?", Rivista Critica di Diritto Privato, 2010, 337.

88 Lombardi Vallauri, loc. ult. cit.

89 Ibíd.

90 Para una "crítica radical" cfr. P. BecchI, "Definizione e accertamento della morte: aspetti normativi", en Il governo del corpo, cit., II, 2082 ss. 
la utilización para la investigación, sin plantearse el interrogante sucesivo -reenviado al legislador- sobre la imposición del 'sacrificio' a los “solos embriones afectados por la enfermedad [...] o también a aquellos que científicamente no pueden someterse a biopsia"9ז.

Parece una perspectiva doblemente falseada.

La destinación del embrión a la investigación tiene el significado de una 'donación', que sirve, en cierta medida, para 'ennoblecer' el 'sacrificio'.

En todo caso, luego no pueden admitirse jerarquías de valores entre embriones 'sanos' y embriones ‘enfermos'. Por lo demás, con referencia a estos últimos, la Corte Constitucional ya había establecido el principio según el cual una discapacidad de estos "no justifica per se un tratamiento desfavorable" 92 , en todo caso -vale la pena agregar-, discriminatorio. Su 'elección' podría justificarse -como parecía suceder en el caso ‘florentino'93- solamente por la peculiar finalidad científica de la investigación.

\section{Algunas pocas ideas para el legislador que quiere intervenir}

Estando atrapado entre adquisiciones jurisprudenciales y principios constitucionales, ¿puede el legislador formular de manera plausible una respuesta positiva (en el sentido de solución de derecho positivo) al interrogante apenas formulado?

Para ello es necesario dar un paso atrás y retomar un dato sorprendente verificable en la "muy discutible" 94 sentencia Parrillo c. Italia que, aunque se haya aventurado desde las premisas en una esmerada revisión de los "elementos de derecho comparado"95, parece "escasamente orientadora" 96 .

$\mathrm{Al}$ valorar ex professo estos documentos, mencionando específicamente a "los Estados miembros que adoptaron un enfoque permisivo", los que "prohíben expresamente cualquier investigación sobre las células embrionarias" y los que "permiten estos tipos de investigación solo en condiciones precisas"97, escapa a la atención de la Corte la peculiar solución legislativa usada por Francia, que constituye un modelo, sin duda, más avanzado en comparación con los enfoques del último tipo recordados antes.

En todo caso, este modelo podría servir, con algunos límites (cfr. infra nota 98), como punto de referencia para un legislador orientado a resolver positiva-

9I Corte const., I3 de abril de 2016, n. 84, cit., n. I I.

92 Corte const., I I de noviembre de 20 I 5 , n. 229 , cit., n. 3.

93 Trib. Firenze, I 2 de diciembre de 2012 , cit., n. 3, 60 I.

94 G. Casaburi, La Corte costituzionale e la l. 40/o4, cit., I 549.

95 Corte Tedh, 27 agosto 20 I 5, cit., nn. 69-76.

96 A. Vallini, Gli ultimi fantasmi della legge 4o, cit., 78.

97 TEDH, 27 agosto 2015 , cit., nn. I 77-I 78. 
mente el problema examinado. Es oportuno sintetizar la estructura y los objetivos.

Este modelo postula el "respeto de los principios fundamentales de la bioética" y, en particular, la observancia del "respeto del ser humano desde el comienzo de la vida" prescrito por el artículo I6 del Code civil (art. L.2 I4I-I); tiene fundamento en las normas del Code de la santé publique introducidas por la ley sobre la bioética (Ley n. ${ }^{\circ}$ 2004-800 del 6 de agosto de 2004, llamada Petite Loi) y queda abierto a las modificaciones requeridas por la evolución del sistema normativo.

El sistema actual, actualizado a enero 2016 (Ley 20I6-4I) está construido sobre las siguientes bases. El monitoreo de la persistencia del proyecto parental, y/o de la bienvenida por parte de otra pareja, está reconocido como presupuesto para la conservación del embrión (art. L.2 I4I-4). En cambio, la constatación del hecho de que un embrión "ya no es objeto del proyecto parental" o "no fue bienvenido" por otra pareja es el presupuesto de un proveimiento que "termina con la conservación del embrión si la duración de esta última es de al menos cinco años" (art. L. 2 I4I-4). El abandono del proyecto parental puede consentir una destinación a la investigación científica, después de la autorización de la Agence de la biomédicine ${ }^{9}$, bajo el entendido de que un protocolo de investigación puede ser autorizado solo si: la pertinencia científica de la investigación está establecida; la investigación, fundamental o aplicada, se inscribe en una finalidad médica; la investigación no se puede hacer sin recurrir a esos embriones; el proyecto y las condiciones de operatividad del protocolo respetan los principios éticos relativos a la investigación sobre el embrión (art. L.2 I 5 I-5, inc. I).

\section{XIII. ¿Qué queda de la Ley 4o? La subjetividad del embrión}

En Italia -se ha dicho- "no parece poder especularse en relación con una próxima modificación legislativa"99. Pero si las ideas de reforma sugeridas por el modelo francés, considerado "el más moderado" Ioo, afectaran la raíz, ¿¿necesariamente caería la última rama que cuelga del árbol de la Ley 40, la subjetividad del embrión?

No creo. Tuve la oportunidad de escribir que es justamente el respeto $b u$ mano, antes que el legal, por esta subjetividad el que impone salir da un silencio cómplice para tutelar positivamente la vida de los embriones crioconservados "en

$9^{8}$ Además, el artículo 2 I 5 I-5 precisa en el segundo inciso que "la investigación no puede hacerse sin el consentimiento previo y escrito de la pareja de la cual proviene el embrión". Aquí, la destinación a la investigación parece configurarse como alternativa "privada", aunque autorizada, a la previsión que "pone fin a la conservación", revelando un componente, por así decirlo, que cosifica la disciplina normativa introducida. Sobre el punto cfr. también infra xIII. 
la medida de lo posible" y para regular, también positivamente, las consecuencias de la constatada imposibilidad ${ }^{\text {Ior }}$.

Los recientes intentos por justificar la destinación de embriones supernumerarios a la investigación, en términos de hipotética ponderación de intereses, revelan el intento de tomar un 'atajo', reduciendo todo a una manifestación de la libertad de autodeterminación de los únicos sujetos (los llamados padres) considerados titulares de derechos subjetivos ${ }^{\mathrm{IO} 2}$. Todo bajo la premisa de que "la subjetividad del concebido de la que se ocupa genéricamente el artículo I de la Ley 40 de 2004 debe entenderse en términos relativos y peculiares" ${ }^{\text {IO3 }}$-en el sentido de que "a tales embriones no se adapta la noción tradicional de los concebidos" I04- en una perspectiva lato sensu cosificadora, que no ha encontrado el favor del $\mathrm{TEDH}^{\mathrm{IO}}$.

La extensión del principio de la subjetividad del concebido al embrión no implantado in utero, con el mismo criterio de una razonable interpretación de la norma apenas mencionada, evidencia la falacia del 'atajo'. La destinación a la investigación no puede ser una fuente 'privada' de supresión del embrión; podría, si acaso, volverse una conclusión de la verificación 'pública' de su muerte, y (solo) así reflejar el deseo de donación de los llamados padres, traducido en un protocolo de investigación debidamente autorizado.

De todas maneras, el embrión no deseado, enfermo, abandonado, olvidado, en cuanto sujeto jurídico y como tal titular de derechos subjetivos, no pudiendo aspirar a nacer con dignidad, debe ser puesto en condiciones de 'morir' con dignidad.

io Permítaseme el reenvío a Busnelli, Cosa resta della legge 40 ? , cit., 467.

IO2 Claramente en tal sentido, Trib. Firenze, i 2 de diciembre de 20 I 2 , cit. Pero la admisibilidad de un derecho a la autodeterminación, ahora entendido también por parte de la Corte Constitucional (supra v) como "una fórmula local que retoma, y pretende reconducir en el ordenamiento el derecho a la vida privada y familiar" de fuente europea, suscita "una preocupación fundada": aquella de la "dificultad [...] de establecer límites para circunscribir el acceso a la procreación asistida [...], evitando que dicho acceso pueda volverse un medio para satisfacer idiosincrasias o caprichos banales, o bien indeseables voluntades eugenésicas": U. SALANitro, "I requisiti soggettivi per la procreazione assistita: limiti ai diritti fondamentali e ruolo dell'interprete", en Nuova giurisprudenza civile commentata, 2016 , II, I364.

I03 A. VAllini, Gli ultimi fantasmi, cit., 69.

I04 M. Rizzutı, "Il problema di definire la vita nascente", en Le definizioni nel diritto, cit., 263. "A los embriones crioconservados, siempre que se compruebe su existencia, será más razonable aplicarles la disciplina de los concebidos, conformada con el objetivo de regular situaciones caracterizadas por la fuerte aleatoriedad y la remota futuridad del nacimiento": esta es la definición -a decir verdad, discutible- propuesta por el autor, quien, entre otras, no deja de precisar que "es distinto el problema de la definición del embrión para los fines específicos de la ley sobre la procreación asistida, que son aquellos de contrastar cualquier forma de cosificación, de la comercialización a la utilización para fines de investigación científica”: ibíd., 264.

IO5 TEDH, Gran Sala, 27 de agosto de 201 5, cit., es resoluta al negar que el embrión pueda ser objeto de "propiedad" o "posesión". 
Esta no es una conclusión que pueda conducir al escándalo o a inquietar o, incluso, a repugnar a la conciencia. Inquietante podría ser, eventualmente, la razón de su 'sacrificio'.

Queda, e induce a la reflexión, el mensaje de Francisco: "Cuando no se reconoce en la realidad misma el valor de un pobre, de un embrión humano [...] difícilmente se escucharán los gritos de la misma naturaleza"ıo6.

\section{Referencias}

Auletta, T., "Ammissibilità nell'ordinamento vigente del matrimonio fra persone del medesimo sesso", Nuova giurisprudenza civile commentata, 20 I 5, I, 654 ss.

Becchi, P., "Definizione e accertamento della norte: aspetti normativi”, en S. Rodotá y P. Zatti (dirs.), Trattato di biodiritto, Il governo del corpo, S. Canestrari, G. Ferrando, C. M. Mazzoni, S. Rodotà y P. Zatti (eds.), t. iI, Milano, 201 I, 2082 ss.

Busnelli, F. D., "Architetture costituzionali, frammenti europei, incursioni giurisprudenziali, rammendi legislativi”, en M. Gorgoni (ed.), Unioni civili e convivenze di fatto ( $L$. 20 maggio $2016, n .76$ ), Santarcangelo di Romagna, 20I6, xxII ss.

Busnelli, F. D., "Cosa resta della legge 40? Il paradosso della soggettività del concepito", Rivista di Diritto Civile, 20 I I, II, 467 ss.

Busnelli, F. D., "Di chi è il corpo che nasce", en C. M. Mazzoni (ed.), Per uno statuto del corpo, Milano, Giuffrè, 2008, I I I-I 24.

Busnelli, F. D., "Il diritto della famiglia di fronte al problema della difficile integrazione delle fonti", Rivista di Diritto Civile, vol. 62, n. ${ }^{\circ}$ 6, 2016, I447-I478.

Busnelli, F. D., "L'inizio della vita umana", Rivista di Diritto Civile, 2004, I, 533-568.

Busnelli, F. D., voz “Statuto giuridico dell'embrione”, en Enciclopedia di Bioetica e di Scienza giuridica, xI, Edizioni Scientifiche Italiane, Napoli, 2 I07, 865-888.

Carusi, D., "In vita, 'in vitro', in potenza. Verso una donazione dell'embrione soprannumerario?", Rivista Critica di Diritto Privato, 2010, 337 ss.

Casaburi, G., "La Corte costituzionale e la 1. 40/04: ritorno all'ordine?”, Nuova giurisprudenza civile commentata, $2013, \mathrm{I}, 589$.

Castronovo, C., "Fecondazione eterologa: il paso (falso) della Corte costituzionale", Europa e Diritto Privato, 20I4, I I 23 ss.

Contr, R., "La dignità umana dinanzi alla Corte di Giustizia", Corriere Giuridico, 2005, 486 ss.

Costantino, "Individui, gruppo e coppie (libertà illusioni passatempi)", Foro italiano, I, I37I Ss.

De Rosa, G., "Scienza, tecnica e diritto in recenti applicazioni giudiziale della disciplina in materia di procreazione medicalmente assistita", Nuova giurisprudenza civile commentata, 2013, I, 6 13 ss.

Io6 Francisco, Laudato si', cit., n. i I 7 . 
Di Masi, M., "Definire la morte; tra diritto e biopolitica", en F. Cortese y M. Tomasi (eds.), Le definizioni nel diritto. Atti delle giornate di studio 30-3I ottobre 2015, Trento, 2016,276 ss.

Ferrando, G., "Autonomia delle persone e intervento pubblico nella riproduzione assistita. Illegittimo il divieto di fecondazione eterologa", Nuova Giurisprudenza Civile Commentata, 2014, II, 393 ss.

Ferrando, G., "Come d'autunno sugli alberi le foglie. La Legge n. 40 perde anche il divieto di diagnosi preimpianto", Nuova giurisprudenza civile commentata, 2015, II, $5^{82}$ ss.

Ferrando, G., "Le diagnosi preimpianto, dunque, sono ammissibili”, Nuova giurispruden$z$ a civile commentata, $20 \mathrm{I} 3, \mathrm{II}, 20$ ss.

Ferrando, G., Fecondazione in vitro e diagnosi preimpianto dopo la decisione della Corte costituzionale, Nuova giurisprudenza civile commentata, 2009, II, 52 I ss.

Francisco, Laudato sì. Carta encíclica sobre el cuidado de la casa común, Tipografía Vaticana, Ciudad del Vaticano, 24 de mayo de 2015, n. 229, disponible en: http://w2.vatican.

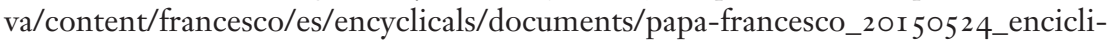
ca-laudato-si.html

Gambaro, A., "Categorie del diritto privato e linguaggio delle carte dei diritti fondamentali", Rivista di Diritto Civile, 2016, I 225 ss.

Lecaldano, E., "La questione della morte. Definizione tra etica e filosofia”, en S. Rodotà y P. Zatti (dirs.), Trattato di biodiritto, Il governo del corpo, editado por S. Canestrari, G. Ferrando, C.M. Mazzoni, S. Rodotà, P. Zatti, t. il, Milano, 20 i i, 2025 ss.

Lenti, L., "Note critiche in tema di interesse del minore", Rivista di Diritto Civile, 2016, IO5 ss.

Liberali, "La sentenza della Corte europea dei diritti dell'uomo in tema di procreazione medicalmente assistita di tipo eterologo", Giurisprudenza Civile Commentata, 20 го, II, 556 ss.

Lombardi Vallauri, L., "L'embrione e le vite diversamente importanti”, en S. Rodotà (ed.), Questioni di bioetica, Roma-Bari, I993, 36 I ss.

Mazzoni, C. M. "Vita e non vita in Cassazione. A proposito di Cass. N. 25767/2015", Nuova giurisprudenza civile commentata, 2016, I, 46I ss.

Meli, M., "Il divieto di fecondazione eterologa e il problema delle antinomie tra diritto interno e Convenzione europea dei diritti dell'uomo", Nuova giurisprudenza civile commentata, $20 \mathrm{I}$ I, II, I 4 ss.

Murgo, C., "La Grande chambre decide sulla fecondazione eterologa e la rimette all'apprezzamento degli Stati contraenti", Nuova giurisprudenza civile commentata, 2OI 2, I, 233 ss.

Padovani, T., “Commento dell'art. i9”, en C. M. Bianca y F. D. Busnelli, “Commentario della Legge 22 maggio I978, n. I94", Nuove leggi civili commentate, I978, I 705 ss.

Pardini, "Libertà di ricerca scientifica e tutela dell'embrione", Nuova Giurisprudenza Civile Commentata, 2016, II, 798 ss. 
Pardini, C., "La diagnosi preimpianto al vaglio della Corte europea dei diritti dell'uomo: influenza delle pronunce nel panorama italiano", Nuova Giurisprudenza Civile Commentata, 20I3, I, 80 ss.

Piraino, F., "I confini della responsabilità civile e la controversia sulle malformazioni genetiche del nascituro: il rifiuto del c. d. danno da vita indesiderata", Nuova giurisprudenza civile commentata, $20 \mathrm{I} 6, \mathrm{I}, 450 \mathrm{ss}$.

Ромiato, R., "Diagnosi preimpianto e tutela dell'embrione: un equilibrio ancora precario", Europa e Diritto Privato, 2016, 236 ss.

Romano, R., "Certezza del diritto, incertezza della scienza: della brevettabilità dei metodi di produzione di linee di cellule staminali da partenoti", Nuova giurisprudenza civile commentata, 2014, II, p. 362 .

Romano, R., "La brevettabilità delle cellule staminali embrionali umane", Nuova giurisprudenza civile commentata, 201 2, II, 233 ss.

Rомвоц, R. "Per la Corte costituzionale le coppie omosessuali sono formazioni sociali, ma non possono accedere al matrimonio", Foro italiano, I, I367 ss.

Salanitro, U., "I requisiti soggettivi per la procreazione assistita: limiti ai diritti fondamentali e ruolo dell'interprete", Nuova giurisprudenza civile commentata, 2016 , II, I 36 ss.

Senigaglia, R., Status filiationis e dimensione relazionale dei rapporti di famiglia, Napoli, 2013 .

Tettamanzi, D., Bambini fabbricati. Fertilizzazione in vitro, embryo transfer, Casale Monferrato, 1985 .

VALLINI, "Gli ultimi fantasmi della legge '40: inconstituzionale il (supposto) reato di selezione preimpianto", Diritto penale e processo, 2016, 74 ss.

\section{Jurisprudencia europea e italiana}

TEDH, Gran Sala, Io de abril 2007, n. 6339/2005, N. Evans v. Reino Unido.

TEDH, sección I, I de abril de 2010 , S.H. et alli c. Austria.

TEDH, Gran Sala, 3 de noviembre de $20 \mathrm{I}_{\mathrm{I}}$, n. 578I $3 / 00$, S.H. et alli c. Austria

TEDH, 28 de agosto de 201 2, n. 54270/Io, Costa y Pavan c. Italia.

Tedh, Gran Sala, 27 de agosto de 2015, n. 4670/ i I, Parrillo c. Italia

Tribunal de Justicia de la Unión Europea, I 4 de octubre de 2004, C-36/o2, Omega Sielhallen —und Automatenaufstellungs GmbH v. Oberburgermein der Bundesstadtsterin Bonn.

Tribunal de Justicia de la Unión Europea, ord. I 7 de marzo 2009, C-2 I 7/o8, Mariano vs. Inail.

Tribunal de Justicia de la Unión Europea, i 8 de octubre de 20 I I, causa C-34/ıo, O(livier) B(rüstle) v. Greenpeace y V.

Tribunal de Justicia de la Unión Europea, I 8 de diciembre de 2014, causa C-364/I3, caso Comptroller.

Corte Constitucional, 8 de mayo de 2009, n. I40. 
Corte Constitucional, 8 de mayo de 2009, n. I 5 I.

Corte Constitucional, 5 de abril de 2010, n. 138.

Corte Constitucional, ro de junio de 2014, n. I62.

Corte Constitucional, 5 de junio de 2015 , n. 96.

Corte Constitucional, 13 de abril de 2016, n. 84 .

Corte de Casación, 9 de febrero de 20 I $_{5}$, n. 2400.

Corte de Casación, Secciones Unidas, 22 de diciembre 201 5, n. 25767.

Trib. Catania, 2 I de octubre de 20 Io.

Trib. Catania, I 3 de abril de 2013.

Trib. Firenze, 6 de septiembre de 20 Io.

Trib. Firenze, I 2 de diciembre de $20 \mathrm{I} 2$.

Trib. Firenze, 29 de marzo de 2013.

Trib. Milano, 2 de febrero de 20 I I. 